\title{
D.S.Collis Bromers's
}
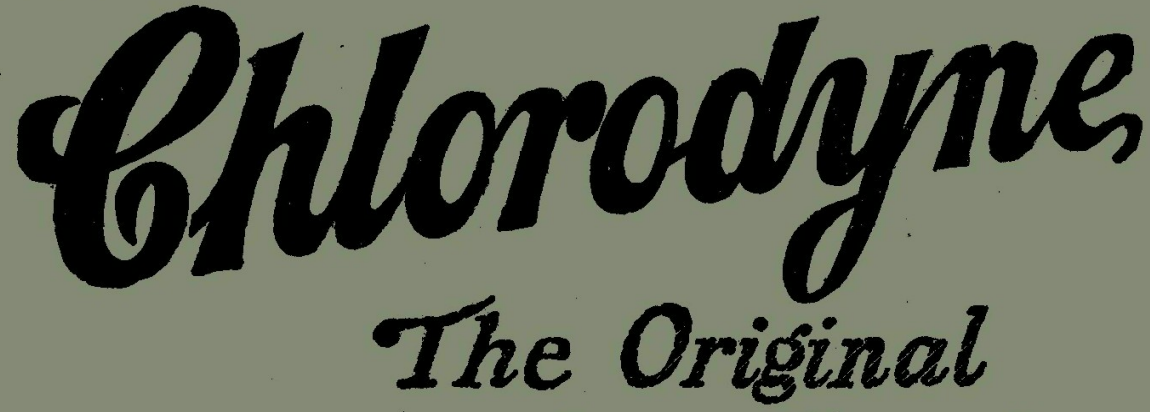

and Only Genuine

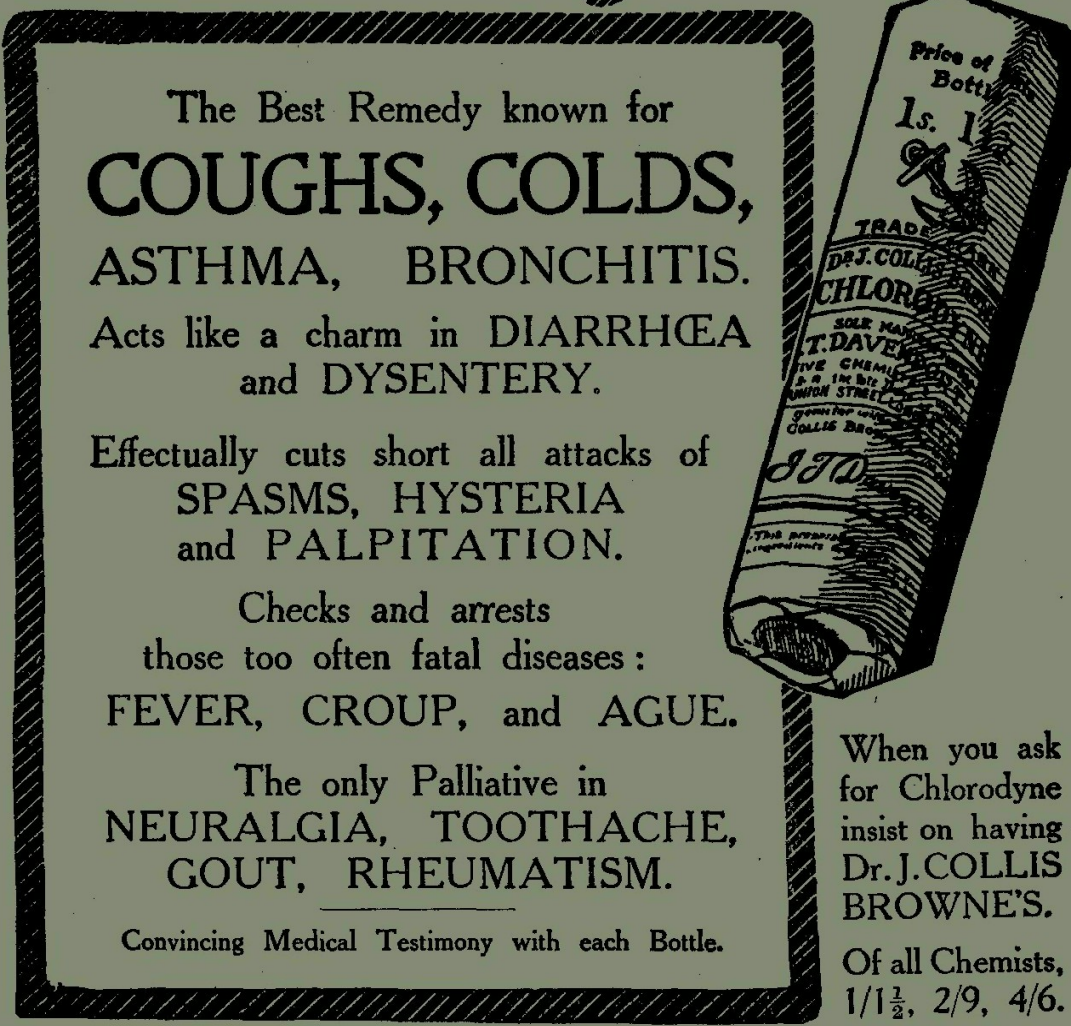

\section{THE MOST VALUABLE MEDIGINE EVER DISCOVERED.}




\section{ROYAL ASIATIC SOCIETY}

\section{or \\ GREAT BRITAIN \& IRELAND. \\ 22 Albemarle Street, Piccadilly, $W$.}

\section{Special Motice.}

THE ROYAL ASIATIC SOCIETY publishes Quarterly an illustrated Journal, containing Original Articles on the Languages, the Archæology, the History, the Beliefs, or the Customs of the East.

The Annual Subscription to the Society is THREE GUINEAS a Year for Resident, and THIRTY SHILLINGS a Year for Non-Resident, Members.

\section{Compositions.}

Members may compound for their subscriptions at the following rates:Resident Members for life $\quad \ldots \quad \ldots \quad \ldots \quad \ldots \quad 45$ guineas Non-resident or Library Members for life $\quad \ldots \quad \ldots \quad 22 \frac{1}{\frac{1}{2}} \quad$ "

Each Member who has paid his Subscription for the current year receives the Journal post free, has the use of the Library at the Society's rooms, and admission to the meetings of the Society. Members paying three guineas may also borrow books.

Libraries and Non-Members may obtain the Journal postfree by a Subscription of Thirty Shillings a year if paid in advance direct to the Secretary. The Price of each Part separately is Twelve Shillings. 